\title{
Solar Power System Design for the Solar Probe+ Mission
}

\author{
Geoffrey A. Landis ${ }^{*}$ and Paul C. Schmitz ${ }^{\dagger}$ \\ NASA John Glenn Research Center, mailstop 302-1, 21000 Brookpark Road, Cleveland OH 44135 \\ James Kinnison ${ }^{\ddagger}$, Martin Fraeman, Lew Roufberg, Steve Vernon ${ }^{\S}$, and Melissa Wirzburger \\ Johns Hopkins University, Applied Physics Laboratory, 11100 Johns Hopkins Road, Laurel, MD 20723
}

\begin{abstract}
Solar Probe+ is an ambitious mission proposed to the solar corona, designed to make a perihelion approach of 9 solar radii from the surface of the sun. The high temperature, high solar flux environment makes this mission a significant challenge for power system design. This paper summarizes the power system conceptual design for the solar probe mission. Power supplies considered included nuclear, solar thermoelectric generation, solar dynamic generation using Stirling engines, and solar photovoltaic generation. The solar probe mission ranges from a starting distance from the sun of $1 \mathrm{AU}$, to a minimum distance of about 9.5 solar radii, or $0.044 \mathrm{AU}$, from the center of the sun. During the mission, the solar intensity ranges from one to about 510 times AMO. This requires power systems that can operate over nearly three orders of magnitude of incident intensity.
\end{abstract}

\section{Nomenclature}

$\begin{array}{ll}\mathrm{A}_{\mathrm{r}} & =\text { Radiator area }\left(\mathrm{m}^{2}\right) \\ \mathrm{I} & =\text { incident intensity }\left(\mathrm{W} / \mathrm{m}^{2}\right) \\ \mathrm{P}_{\text {electric }} & =\text { power generated }(\mathrm{W}) \\ \mathrm{R}_{\mathrm{S}} & =\text { solar radius }(696000 \mathrm{~km}) \\ \mathrm{T} & =\text { temperature }(\mathrm{K}) \\ \mathrm{Th} & =\text { hot-end temperature of thermal conversion system }(\mathrm{K}) \\ \mathrm{Tc} & =\text { cold-end temperature of thermal conversion system }(\mathrm{K}) \\ \alpha & =\text { solar absorptivity (equal to } 1 \text { minus the reflectivity) } \\ \varepsilon_{\mathrm{f},}, \varepsilon_{\mathrm{r}} & =\text { thermal }(\mathrm{IR}) \text { emissivity of the front and rear surfaces } \\ \eta & =\text { conversion efficiency } \\ \sigma & =\text { Stefan-Boltzmann constant, } 5.67 \times 10^{-8} \mathrm{~W} / \mathrm{m}^{2} \mathrm{~K}^{4}\end{array}$

\section{Background} The Solar Probe + mission $^{1,2}$ represents a challenging mission to send a spacecraft to explore the region close to
the sun.

The proposal for a probe to fly directly into the solar corona, the source of the solar wind, was initially proposed in the mid-1970s. Earlier concepts ${ }^{3-8}$ for the mission incorporate a Jupiter flyby, to use the "gravitational slingshot" effect to cancel the Earth's orbital angular momentum, allowing the spacecraft to drop nearly directly toward the sun. This results in a mission concept which has a long flight duration before the solar encounter, and is relatively expensive, in part because of the need to incorporate a power supply which can operate both at the low intensity, low temperature environment of Jupiter orbit (about $4 \%$ of the solar intensity at Earth orbit), as well as the high intensity high temperature environment near the sun.

In 2007, NASA tasked the Applied Physics Laboratory to conduct a study to determine the feasibility of a lowercost, non-nuclear mission that would achieve the Solar Probe science objectives ${ }^{1}$. The mission requirements imposed a significant challenge to meet the objectives: design a mission that meets difficult science objectives while mitigating the effect of the near-solar environment on spacecraft systems, develop a power system that would provide power from Earth escape through the solar encounter, and develop a low-cost spacecraft that can be achieve the required orbit using a cost-effective launch vehicle. APL partnered with Glenn Research Center to perform a

\footnotetext{
* Physicist, Photovoltaics and Power Technology Branch, NASA Glenn Research Center. AIAA Associate Fellow

${ }^{\dagger}$ Engineer, PCS, Inc., Electrochemistry Branch at NASA Glenn Research Center. AIAA member.

* Johns Hopkins University, Applied Physics Laboratory.

${ }^{\S}$ Principle Staff Engineer, Johns Hopkins University, Applied Physics Laboratory. AIAA Senior member.
} 


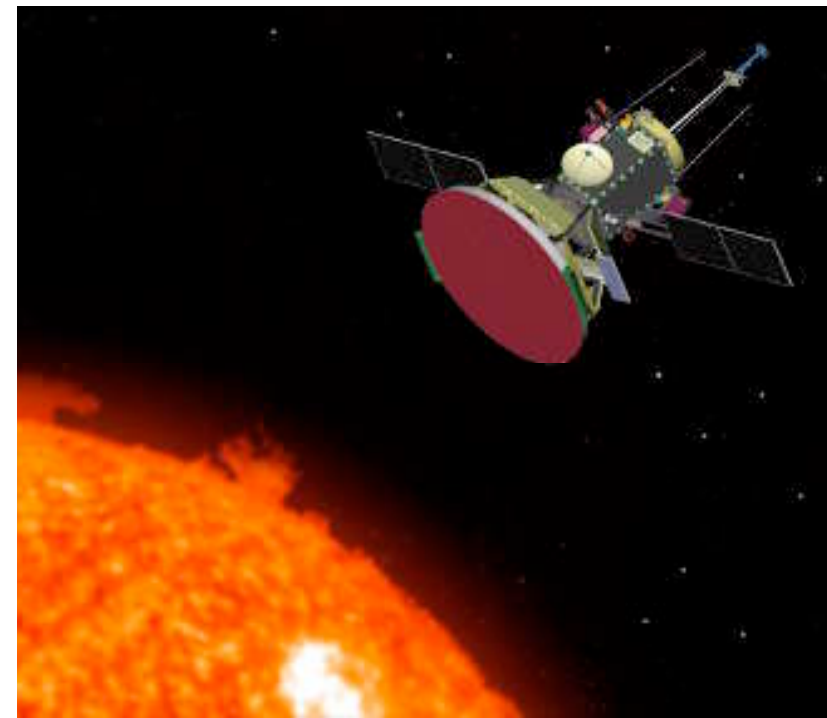

Figure 1: Solar Probe+, a mission to explore the sun's corona. This spacecraft is designed to be operated on photovoltaic power as close as $0.042 \mathrm{AU}$ from the sun. The flat solar shield protects the instrument package from the thermal environment near the sun. (Artist's conception, courtesy http://solarprobe.gsfc.nasa.gov).

spacecraft has previously approached the sun.

Figure 2 shows the final orbit chosen, showing the detailed timing of the final mission encounters consisting of three passes at or within a closest approach distance of 9.5 solar radii (Rs). In this closest approach, only ten hours are spent at a distance inside of ten solar radii.

The primary features of the new orbit include:

- Multiple Venus flybys

- Fast mission, requiring only a few months to get to Venus, rather than years

- Closest approach 9.5 solar radii $(0.044 \mathrm{AU})$

- Solar intensity 510 x AM0

- Solar fly-by repeated many times

The change in orbit allows for the use of photovoltaic power generation through the solar encounter using an innovative, actively cooled solar array system. During the mission, the solar intensity varies from one to about 510 times AM0, or $700 \mathrm{~kW} / \mathrm{m}^{2}$. A significant consideration for the power system is that the power system must be able to operate over nearly three orders of magnitude of incident intensity.
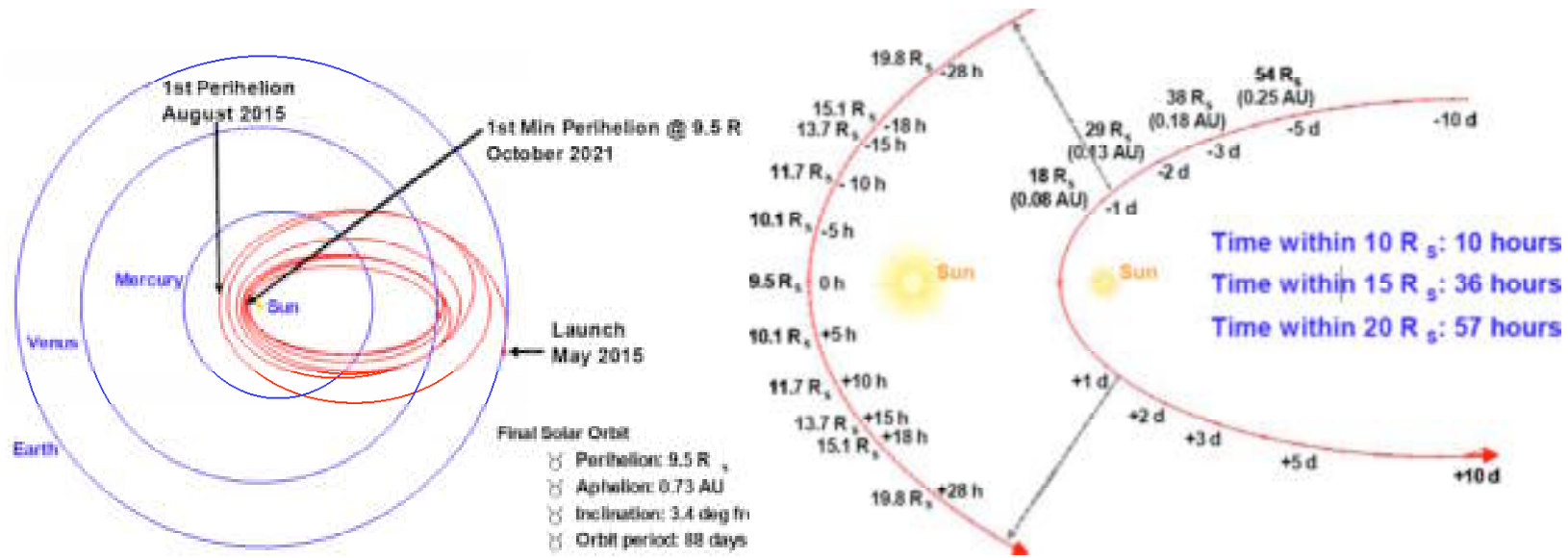

Figure 2: solar probe orbit, with detail of closest approach to the sun

2

American Institute of Aeronautics and Astronautics 092407 
The most difficult criterion for the power system is the ability to operate near the sun. The equilibrium temperature of a surface illuminated by sunlight is achieved when the absorbed incident energy equals the thermally radiated infrared radiation. This can be calculated using the Stefan-Boltzmann equation:

$$
\alpha \mathrm{I}=\left(\varepsilon_{\mathrm{f}}+\varepsilon_{\mathrm{r}}\right) \sigma \mathrm{T}^{4}
$$

where I is the incident intensity; $\alpha$, the solar absorptivity (equal to 1 minus the reflectivity); $\varepsilon$, the thermal (IR) emissivity of the front and rear surfaces (assuming that the surface can radiate from both sides); $\sigma$, the StefanBoltzmann constant, and $\mathrm{T}$, the temperature.

Figure 3 shows the equilibrium temperature of an uncooled flat-plate solar array, assumed to be flat on to the incident sunlight, as a function of the ratio of solar absorption to thermal emissivity (epsilon). As can be seen, even for unrealistically low values of the $\alpha / \varepsilon$ ratio, the equilibrium temperature becomes extremely hot at heliocentric distances inside of Mercury's orbit.

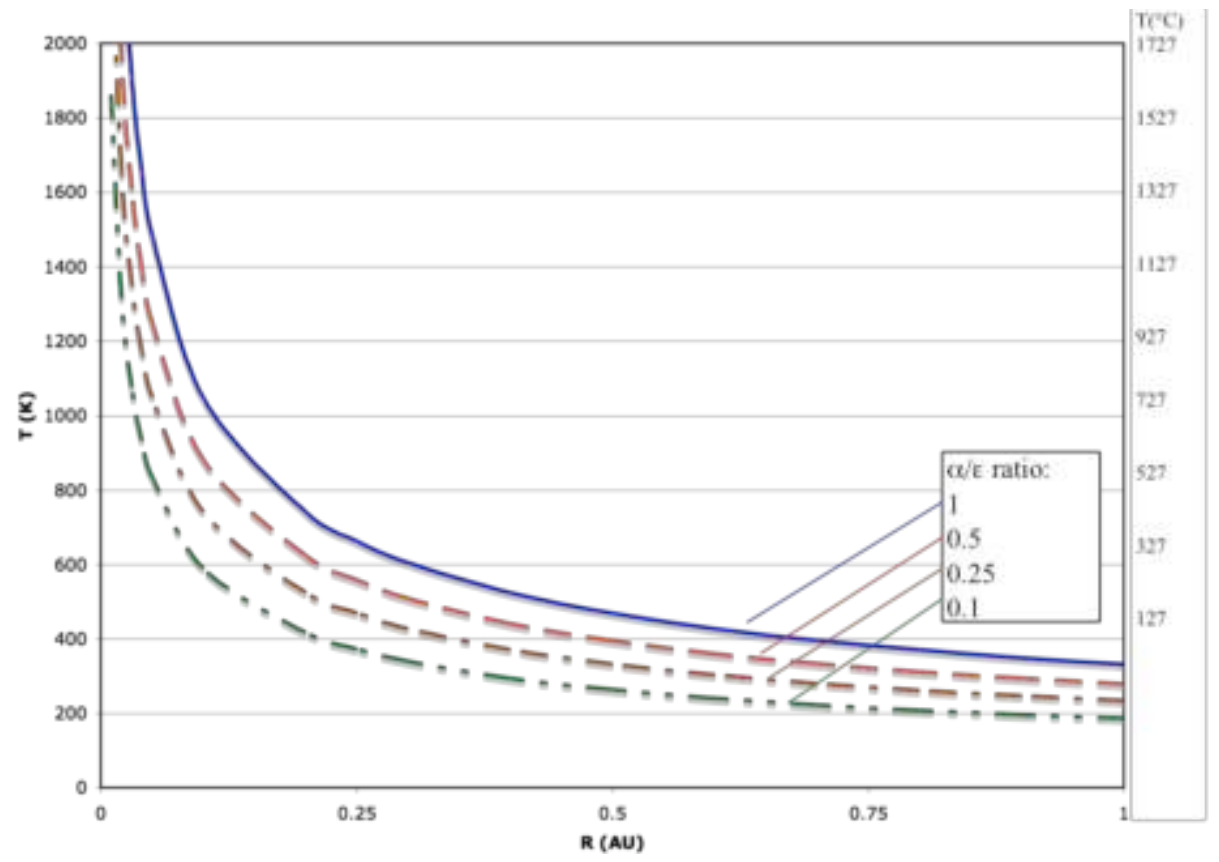

Figure 3: Temperature as a function of distance from the sun, for various values of a/e ratio.

Solar cells decrease in performance as the temperature increases ${ }^{10}$, and are also subject to irreversible degradation leading to eventual failure under exposure to temperatures of roughly $350^{\circ} \mathrm{C}$ and above. While some research has been done on design of solar cells capable of higher temperature operation ${ }^{11-13}$, no existing solar array technologies are designed for operation at high temperature.

\section{MESSENGER Array: an Approach to Solar Arrays for a Near Sun Mission}

Approaches to solar arrays for near-sun missions include modifying any of the terms governing temperature or efficiency of the cell: the incident intensity, solar absorption, emissivity of the surface; or the temperature coefficient of the cells.

As an example of a mission with solar panels designed to operate at high solar flux using the technique of limiting the incident flux to the array and modifying solar absorption $\alpha$, the "MESSENGER" mission to orbit Mercury ${ }^{14}$ has designed an array with mirrored optical surface reflectors covering replacing approximately $70 \%$ of the solar cells across the surface area of the array ${ }^{15}$. These panels reflect $70 \%$ of the incident solar energy, and hence reduce the operating temperature. The mirrors incorporate a high-emissivity silica coating, allowing efficient thermal radiation. These panels have operated (at the first Mercury fly-by) at distance of $0.4 \mathrm{AU}$ from the sun ${ }^{15}$, and have been qualified in thermal vacuum testing to be capable of operating as close as $0.25 \mathrm{AU}$ from the sun, at an intensity of 16 times the intensity at Earth orbit ${ }^{16}$.

The arrays use off-pointing to reduce the incident intensity at Mercury; however, the arrays were designed to tolerate the full on-sun thermal regime, in the case of a pointing failure. 
This array has now successfully demonstrated operation at the nearest approach to the sun of any solar-powered mission. The solar array design used for the ESA "Venus Express" mission and the array being developed for the upcoming Bepi-Columbo Mercury orbiter both used a similar approach to thermal control.

\section{Solar Probe +}

The Solar Probe Plus mission design incorporates several of the methods of decreasing sensitivity to multiple intensities. The minimum power requirement for the mission is 482 Watts.

To deal with the wide variation in solar intensity between the initial operation of the spacecraft at Earth orbital distance and the closest approach, the power system design utilizes two primary power supplies. A conventional solar array is used for the portion of the trajectory from Earth to approx. $0.25 \mathrm{AU}$, where the intensity reaches 16 times the one-sun intensity. As the spacecraft approaches closer to the sun than $0.25 \mathrm{AU}$, these arrays then stow behind the shadow shield to avoid excess thermal exposure. At this distance and inward, a secondary high-flux solar array takes over as primary power source, and is used for the near-sun portion of the mission.

\section{A. Conventional Solar Array}

The main array is used from Earth to slightly inside the Mercury orbit. The array uses the MESSENGER design, described above, incorporating optical surface reflectors into the array to reduce the temperature. Since the MESSENGER array has already demonstrated in flight ${ }^{14}$ and is qualified for distances as low as $0.25 \mathrm{AU}^{16}$, no technology or materials development is needed for the array.

The Solar Probe + primary array design uses two photovoltaic wings, each with a total area of $1.5 \mathrm{~m}^{2}$. The array can be off-pointed from the sun to allow operation in to approximately $0.25 \mathrm{AU}$, an intensity of 16 suns. At this distance the main solar array is folded in behind the shadow shield, where it is not exposed to high temperatures, and the secondary power supply is used.

For this array, the lowest power occurs at the farthest distance from the sun, $1 \mathrm{AU}$, and hence the array is sized to produce the minimum required mission power of $482 \mathrm{~W}$ at this condition. The panel incorporates 32 strings of 39 triple-junction cells. The photovoltaic cell technology baselined is the commercially-available ${ }^{17,18}$ space-qualified triple-junction cell technology, incorporating $\mathrm{GaInP}_{2}, \mathrm{GaAs}$, and $\mathrm{Ge}$ cells which respectively utilize the ultraviolet and blue portion, visible and near IR, and IR portions solar spectrum. The array will incorporate mirrors (optical surface reflectors) at a packing density of 2 reflectors for each cell

As Solar Probe+ approaches the Sun, the array will be tilted up to $\sim 74^{\circ}$ off the Sun to limit the incident solar flux and maintain the array within thermal limits of under $180^{\circ} \mathrm{C}$.

Figure 5 shows the spacecraft with the primary solar arrays deployed.
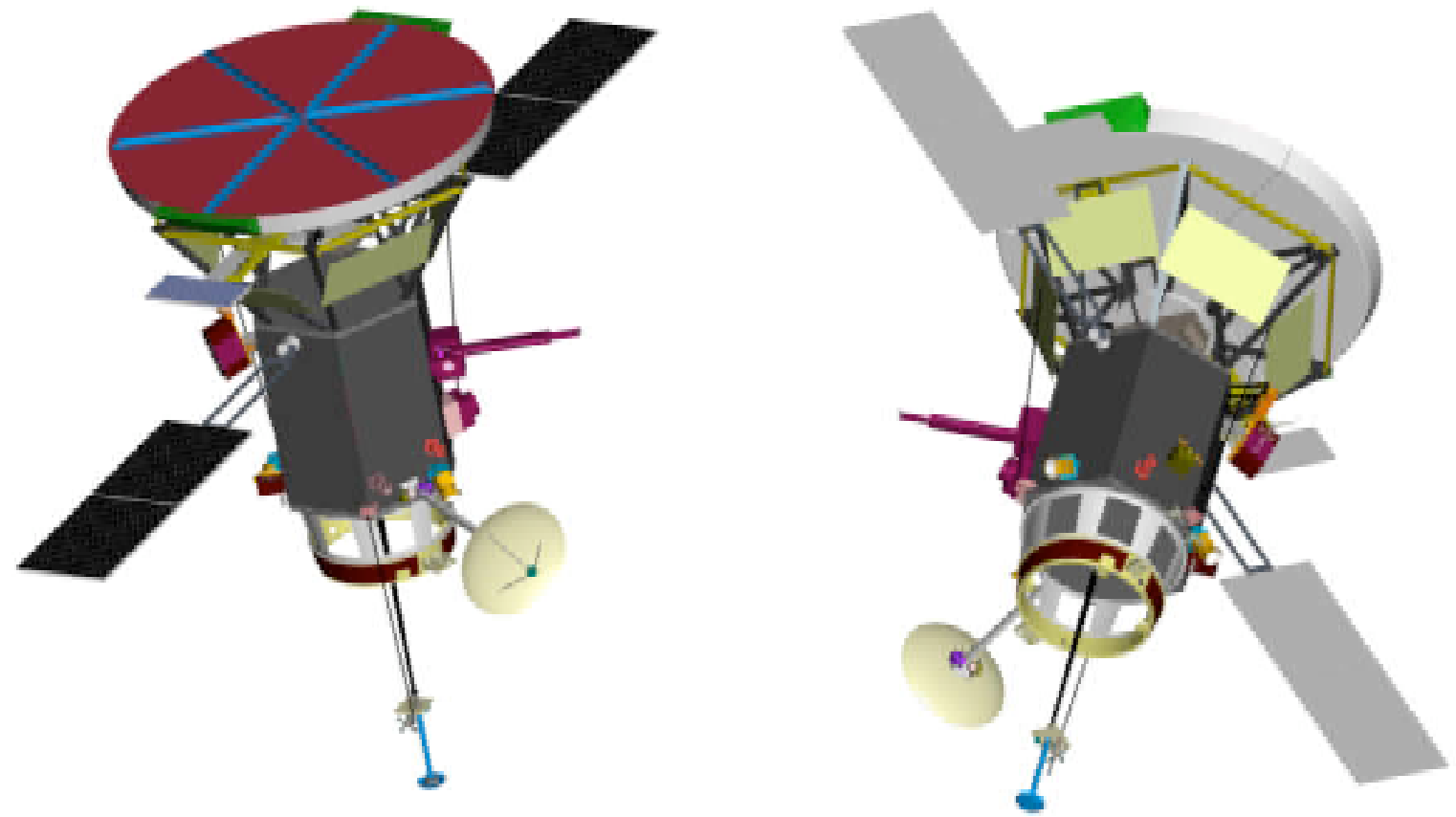

Figure 4: Solar Probe + shown with primary array deployed, showing the spacecraft from the front perspective view (left) and rear (right). 


\section{B. High Intensity Conversion System Design Study}

\section{Background}

Close to the sun, the main part of the spacecraft as well as the primary solar array is shadowed behind the heat shield. The solar power source needed to operate in this regime must operate at intensity from 16 to 510 times AM0 $\left(\sim 700 \mathrm{~kW} / \mathrm{m}^{2}\right)$, a factor of 32 .

As a mission approaches close to the sun, the temperature of a flat-plate exposed to the sun increases. This presents the option of a possible design alternative of converting this heat, using a heat engine, rather than using photovoltaic arrays. Thermal power conversion is a demonstrated technology, and there exists a choice of conversion technologies, including thermoelectric conversion, a technology with comparatively low efficiency, but high spaceflight heritage, or Stirling conversion, which has the advantage of higher efficiency but no spaceflight heritage.

\section{Analysis of Thermal Conversion}

Since a heat engine runs off a temperature differential between hot and cold sides, any thermal conversion system must require a radiator to provide the low temperature "cold side" of the system, which must be not exposed to the sun, either in the shadow of an absorber or the thermal shield, or else edge-on to the incident flux. The radiator must be sized to radiate the waste energy at the cold-side temperature.

The radiator design can dominate the size and mass of the conversion system, and hence analysis of the radiator size is key to the mission design. Figure 5 shows the block diagram of the energy flow in such a thermal system. Since the power produced is proportional to the conversion efficiency $\eta$, and the radiator area proportional to the waste power radiated, which is proportional to (1- $\eta$ ), the radiator area $A_{r}$ depends sensitively on the conversion efficiency and the radiator temperature

$$
\mathrm{A}_{\mathrm{r}}=[(1-\eta) /(\eta)] /\left(\varepsilon \sigma \mathrm{T}^{4}\right)
$$

Emissivity $\varepsilon$ for thermal radiators is typically very close to 1 . If the radiator is two-sided, the area $A$ includes both front and rear sides.

Both thermoelectric conversion and Stirling-cycle heat engines were analyzed. The thermoelectric converters, although well demonstrated in space, had too low efficiency to be viable for the mission.

Stirling converters for the Advanced Radioisotope

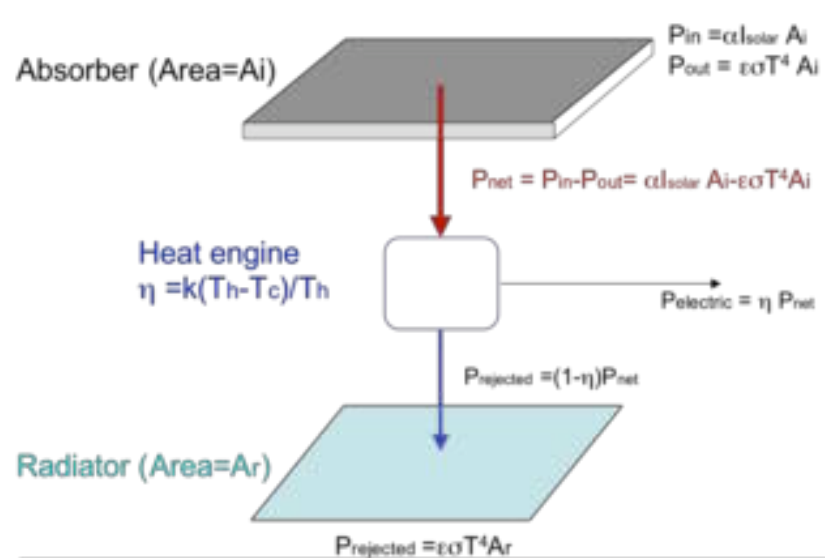

Figure 5: Thermal conversion energy flow block diagram Power Source have demonstrated 38 percent conversion efficiency ${ }^{19,20}$ operating at $850^{\circ} \mathrm{C}$ hot-end temperature $(\mathrm{Th})$ and a $90^{\circ} \mathrm{C}$ cold-end temperatures (Tc). This is slightly over $50 \%$ of the theoretical (Carnot) efficiency. Overall system efficiency, accounting for other losses, is on the order of $26 \%$. These efficiency numbers are roughly comparable to the best photovoltaic technologies. The efficiency scales with temperature as the Carnot efficiency, directly proportional to the difference between the hot- and cold-end temperature, and hence the conversion efficiency increases as the radiator size increases.

The requirement that the thermal system chosen must operate over wide range of intensities, and hence varying hot-end temperatures, represents an engineering challenge for many missions. As can be seen from figure 2, the Solar Probe is only at close approach to the sun for a duration on the order of 10 hours. Over the distance range of operation, the equilibrium temperature of the hot side of the system will vary by factor of $32^{1 / 4}$ $=2.4$. This range of variation is outside of the normal operational bounds of typical thermal conversion systems, which typically operate at a fixed, or nearly fixed, hot-end temperature. Qualifying a conversion system to operate over this thermal input range would require some design effort.

\section{High-intensity solar array: Photovoltaic array}

In the photovoltaic design option, a similar radiator is used to cool the photovoltaic array, keeping the array temperature within the standard operating temperature range. Equation (2) for radiator size can be used for this design as well, where the thermal radiator is used to cool a solar array instead of a heat engine. 


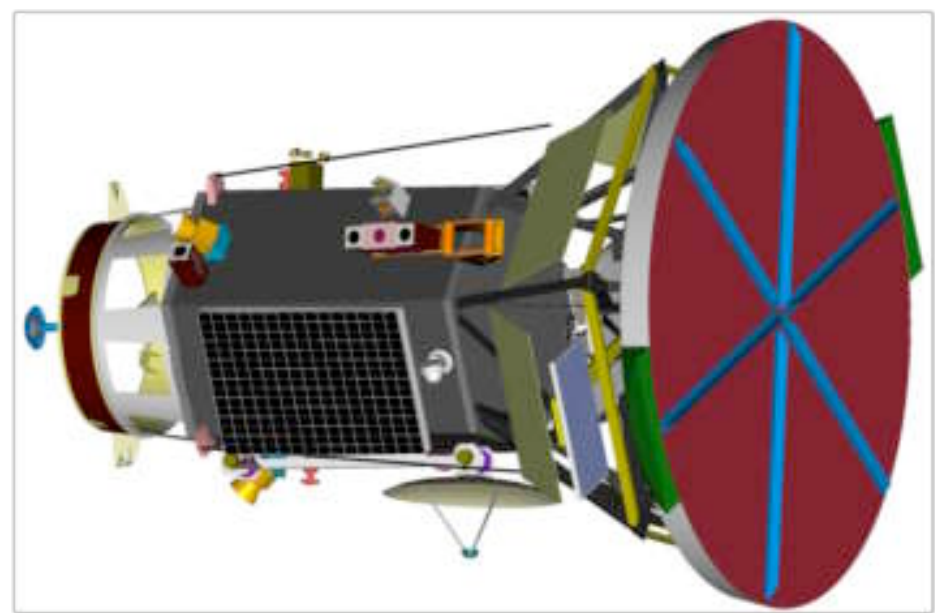

Figure 6: Solar Probe+ conceptual design, showing the primary solar arrays retracted behind the heat shield.
In the design chosen, the secondary solar array will use concentrator solar cells cooled by pumped liquid coolant circulating to radiator. The pumped cooling loop keeps maximum temperature to below $120^{\circ} \mathrm{C}$, the maximum limit allowable by the solar cell design chosen without further qualification testing.

As with the thermal system, the photovoltaic system must also be designed for a wide range of input intensities.

\section{Photovoltaic versus Thermal Conversion Trade-off}

The following considerations were taken into account in calculating the trade-off between thermal and photovoltaic conversion:

\section{Thermal/Stirling conversion:}

- ASRG converter has been demonstrated in ground testing

- Not yet demonstrated in space

- Hot-side Temp (.25 AU, coldest case) $788 \mathrm{~K}$

- $36 \%$ efficiency requires cold side at $315 \mathrm{~K}$

- Efficiency reduced to $28 \%$ at cold side of $420 \mathrm{~K}$

- Assumes hot-side temperature not drawn down by power system

- No significant advantage from spectral selective coatings

- Operation over high dynamic range of input temperature is not yet demonstrated

\section{Photovoltaic conversion:}

- Thermal radiator required to keep cell temperature $<120^{\circ} \mathrm{C}(393 \mathrm{~K})$

- Commercially available technology: baseline concentrator cell efficiency 35\% at AM1.5

- extrapolates to $28 \%$ AM0 efficiency at $120^{\circ} \mathrm{C}$ operating temp

- Radiator size can be decreased if spectral selective coatings are added

Overall, the two systems were roughly comparable in temperature, efficiency and radiator area. However, the photovoltaic option used technology that was more similar to technology that has been flown in space. Furthermore, the mission trajectory requires a very high launch energy (C3). This means that the mission is highly mass constrained, and hence the power supply must be as low in mass as possible. The baseline calculations showed a lower mass for the photovoltaic power system compared to the thermal conversion system.

The thermal conversion option also requires a system that operates at peak efficiency over a wide range of temperatures. While this does not present fundamental barrier to operation, it is a regime that has not been previously developed, and would require some amount of technology development and validation.

For all of these reasons, the photovoltaic power system was chosen as both the lower mass, and also the lower risk option.

\section{High Flux Solar Array Design}

\section{Photovoltaic Cells}

The design chosen for the secondary high-flux power supply uses high-efficiency triple-junction solar cells designed for high solar concentrations. The design uses two identical high-flux arrays, one located on either side of the spacecraft.

The photovoltaic cells selected for this application are commercially-available concentrator solar cells ${ }^{21,22}$. Although these cell designs are designed for terrestrial concentrator application, not for space applications, the cell technology is identical to the space cell technology ${ }^{17,18}$, with the exception that the metallization used for ohmic 
contact to the cell is designed for a higher input solar flux. Since the underlying materials technology is identical to already-qualified space cells, space qualification was not considered to be an issue.

Each panel has 25 parallel strings of liquid-cooled solar cells, with approximately $1 \mathrm{~cm}^{2}$ active area per cell. Each series-connected string incorporates 27 cells and an isolation diode.

The performance specifications for these cells can be obtained from the vendors as a function of both the concentration and the temperature. These specifications are nominally referenced to the terrestrial (Air-mass 1.5 Direct, $850 \mathrm{~W} / \mathrm{m}^{2}$ ) solar spectrum. Because of the spectral difference between this and the space (Air-mass 0, 1367 $\mathrm{W} / \mathrm{m}^{2}$ ) spectrum, the efficiency achieved under space conditions must be slightly recalculated, and is slightly lower than the terrestrial value. Likewise, since the space one-sun intensity is slightly higher than terrestrial one-sun intensity, the effective solar concentration in space conditions must be modified from that of the design specifications. For the assumed operating conditions, the baseline cell conversion efficiency extrapolated to about $28 \%$ under space conditions, at the maximum operating temperature.

The area of the thermal radiator is minimized by operating the solar cells at the highest temperature. The vendor-specified maximum operating temperature for these cells was $120^{\circ} \mathrm{C}$. Although some tests suggest that higher operating temperatures may be possible, a design-maximum temperature of $120^{\circ} \mathrm{C}$ was chosen for the analysis.

Spectrally selective coating designed to reflect the wavelengths of light to which the cells are unresponsive, or have low response, could be used to reduce the temperature of the cells, and hence reduce the amount of waste heat that must be radiated to space by the thermal radiators. Although this approach may be feasible, it was not assumed for the baseline design.

\section{Design for Variable Incident Intensity}

In order to keep the solar cells within the nominal temperature limits, a liquid cooling loop pumps coolant from the cell mounting through thermal radiators mounted on the outside of the spacecraft. The assumed temperature drop across the coolant loop was $20^{\circ}$. Since the cell maximum temperature is $120^{\circ} \mathrm{C}$, the radiators must be sized to reject heat at $100^{\circ} \mathrm{C}\left(373^{\circ} \mathrm{K}\right)$. Each of the two arrays is connected to three thermal radiators, which are located behind the heat shield, and out of the direct solar illumination. Figure 8 shows the solar array substrate and the three

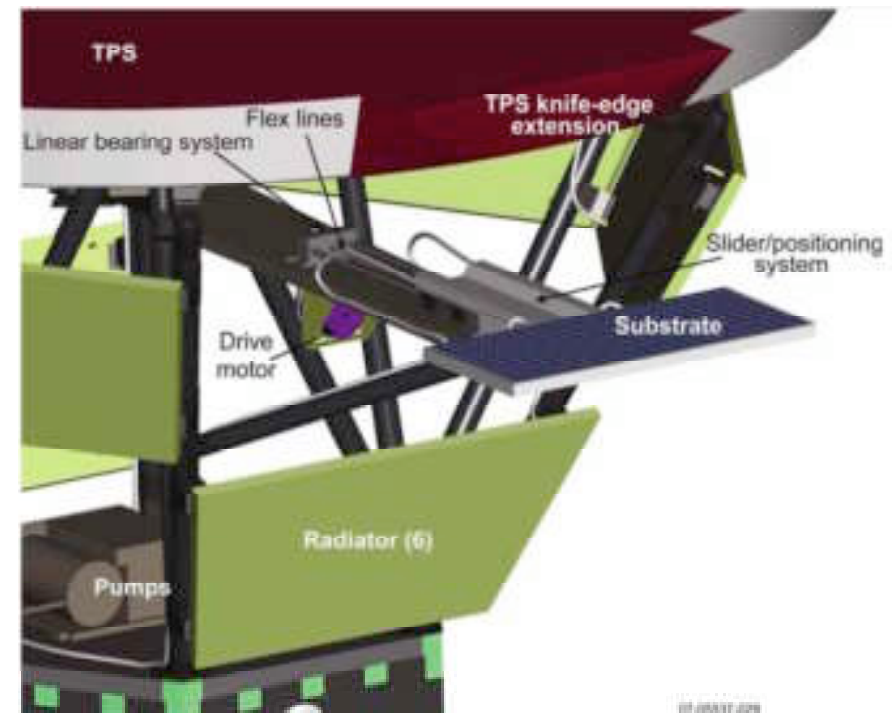

Figure 7: Secondary high-flux solar-array substrate and thermal radiators (labeled). A second solar array, not shown, is located on the opposite side of the spacecraft. thermal radiators. Since the rear side of each radiator is directed toward the spacecraft, heat rejection is by radiation from the front side of the radiator panels only, which are aimed toward space.

The fully-illuminated array is sized to produce $482 \mathrm{~W}$ at the farthest operating distance of $0.25 \mathrm{AU}$. The main size (cost) driver is the cooling radiators. If the array area exposed to sunlight were constant, the radiators required to keep the cells cool at perihelion intensity of 510 suns would be significantly oversized at the farthest distance, receiving only 16 suns intensity. Likewise, the array which is sized to produce full power at $0.25 \mathrm{AU}$ would be significantly oversized at the 32 times higher illumination intensity of perihelion.

To reduce the required radiator size, the illuminated area of the solar cells is reduced as the spacecraft moves from 0.25 AU to perihelion. The secondary solar array is progressively retracted behind the solar shield as it approaches the sun, in order to keep the total incident power

level on the array (and hence the heat load to the radiators) approximately constant.

At closest approach $(9.5 \mathrm{Rs})$, the secondary array panels require a total equivalent cell area of only $34 \mathrm{~cm}^{2}$. Several different mechanisms for retracting the array were analyzed. The mechanism finally adopted involved sliding the solar array linearly back behind a knife-edge shadow-shield affixed to the edge of the main solar heatshield. This is shown in Figure 8. 
The concentrator solar cells in the secondary array are arranged in 27 linear strings, oriented parallel to the knifeedge of the shadow shield. As the solar array retracts behind the shadow shield, the number of strings exposed to solar illumination decreases, until at the closest approach, only the single outermost string is partially illuminated.

Figure 9 shows the secondary array, the associated radiators and coolant pumps, and the structure as they would be viewed with the heat shield removed. Figure 10 shows spacecraft with the relative sizes of the primary and secondary array.
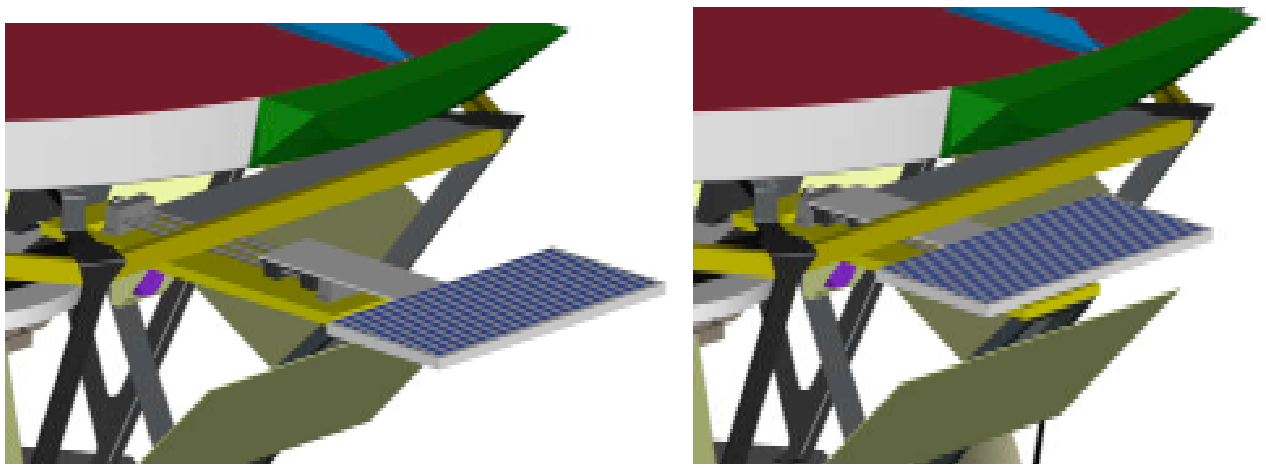

Figure 8: Second solar array, shown in the deployed (left) and retracted (right) configurations.

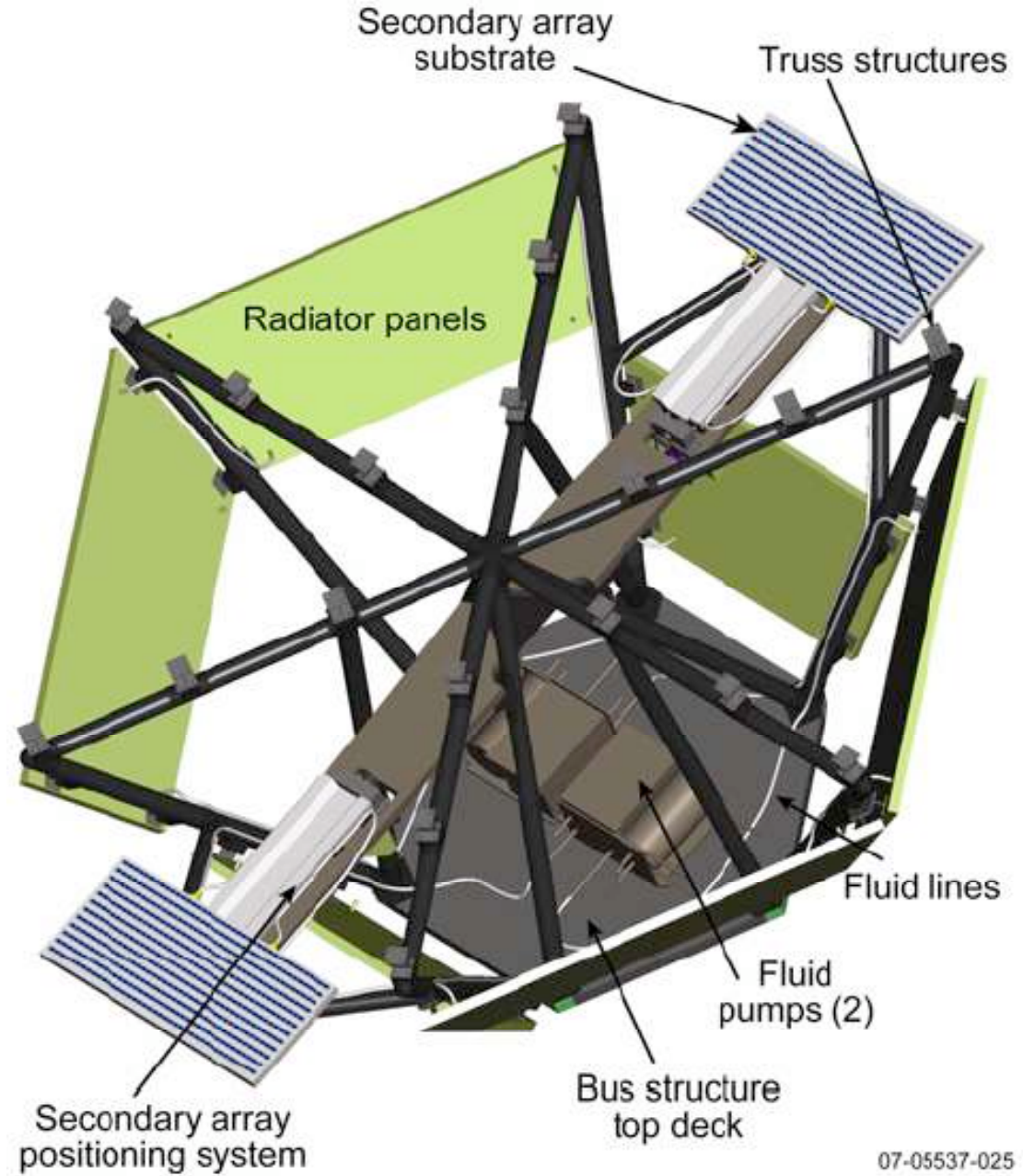

Figure 9: Interior detail of secondary arrays, mechanisms, radiators, and structure. 


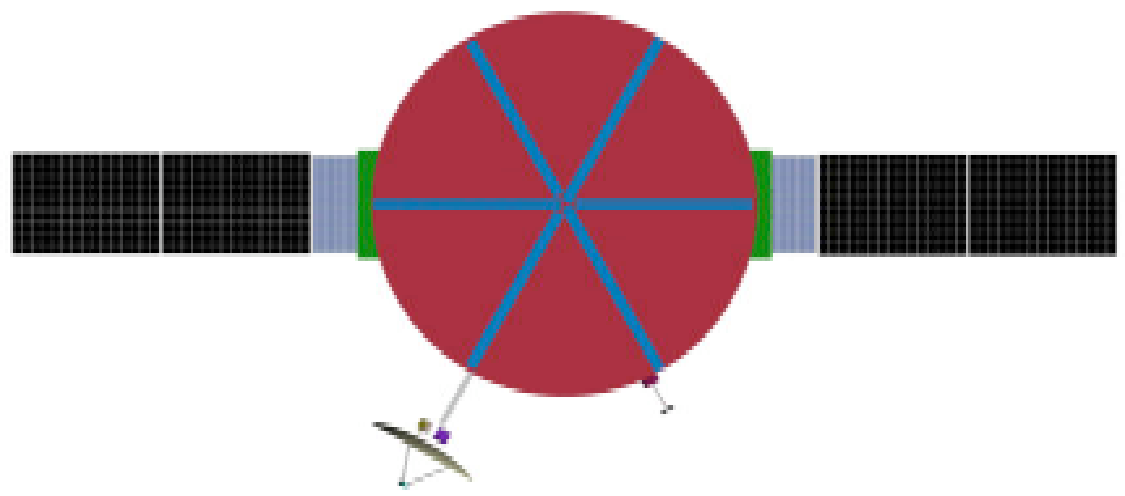

Figure 10: Front view of the final Solar Probe design, viewed from the front (heat-shield) side. Shown to scale with both solar arrays deployed, showing relative sizes of the two arrays.

\section{Conclusion}

Solar Probe is a challenging mission for a solar powered system. The closest approach of 9.5 solar radii is eight times closer to the sun that any spacecraft has ever approached the sun. The solar intensity at closest approach is 510 times AM0

A photovoltaic power supply was designed for the Solar Probe Plus mission, using an innovative approach using pumped cooling loop and a two-power supply solution.

\section{References}

1. Solar Probe+ Mission Engineering Study Report, prepared by The Hohns Hopkins University Applied Physics Laboratory under NASA Contract NNN06AA01C, Laurel, MD (March 10, 2008).

2. J. Kinnison, et al., "The Solar Probe+ Mission: A New Concept for Close Solar Encounters," 59th International Astronautical Congress, Glasgow, Scotland, Sept. 29-Oct. 3, 2008.

3. J. E. Randolph, "NASA Solar Probe Mission and System Concepts," Advances in Space Research, 17, 3, pp. 3-12 (1996).

4. J. E. Randolph, B. T. Tsurutani, P. R. Turner, R. M. Miyake and J. A. Ayon, "Some Options for a Minimum Solar Probe," Physics and Chemistry of The Earth, 22, 5, pp. 481-485 (1997)

5. Robert L. Staehle, et al., "Ice \& Fire: Missions to the most difficult solar system destinations... on a budget," Acta Astronautica, 45, 4-9, pp. 423-439 (Aug.-Nov. 1999).

6. G. Gloecker, et al., Solar Probe: First Mission to the Nearest Star, Report of the Science Definition Team for the Solar Probe Mission, The Johns Hopkins University Applied Physics Laboratory, Laurel, MD (1999).

7. Yanping Guo and Robert W. Farquhar, "Current Mission Design of the Solar Probe Mission," 54th International Astronautical Federation Congress, in Acta Astronautica, 55, pp. 3-9, 211-219 (Aug.-Nov. 2004)

8. D. J. McComas, et al., Solar Probe: Report of the Science and Technology Definition Team, NASA Technical Memorandum TM-2005-212786 (2005).

9. D. Merritt, S. Houlihan, R. Rafaelle, and G. Landis, "Wide Bandgap Space Solar Cell Development," Proc. 21st. IEEE Photovoltaic Specialist's Conference, 2005, pp. 552-555.

10. J. C. C. Fan, "Theoretical Temperature Dependence of Solar Cell Parameters," Solar Cells, 17, 1986, pp. 309-315.

11. G. A. Landis, P. Jenkins, D. Scheiman, and R. Rafaelle, "Extended Temperature Solar Cell Technology Development," Proc. 2nd International Energy Conversion Engineering Conference, paper AIAA-2004-5578, Providence, RI (August 1619 2004)

12. G. A. Landis, R. Rafaelle, and D. Merritt, "High Temperature Solar Cell Development," Proc. 19th European Photovoltaic Science \& Engineering Conf., pp. 3659-3661 (2004)

13. G. A. Landis, "Solar Cells for High-Temperature Near-Sun Missions," 33rd IEEE Photovoltaic Specialists Conference, San Diego CA, May 12-16, 2008.

14. A. G. Santom, et al., "The MESSENGER Mission to Mercury: Spacecraft and Mission Design," Planetary and Space 
Science, 49, No. 14-15, Dec. 2001, pp. 1481-1500.

15. G. Dakermanji, J. Jenkins, and C. J. Ercol, "The MESSENGER Spacecraft Solar Array Design and Early Mission Performance," Proc. 2006 IEEE 4th World Conference on Photovoltaic Energy Conversion, Vol. 2, 2006, pp. $1919-1922$.

16. C. J. Ercol, J.E. Jenkins, G. Dakermanji, A. Santo and L. S. Mason, "Prototype Solar Panel Development and Testing for a Mercury Orbiter Spacecraft," paper AIAA-2000-2881, 2000.

17. Chris Fetzer, Bongim Jun, Kenneth Edmondson, Scott Khemthong, Kaveh Rouhani, Robert Cravens, Rina Bardfield \& Mark Gillanders, "Production Ready 30\% Efficient Triple Junction Space Solar Cells," 33rd IEEE Photovoltaic Specialists Conference, San Diego CA, May 12-16, 2008.

18. Mark A. Stan, Daniel J. Aiken, Arthur B. Cornfeld, Benjamin Cho, Jacqueline Diaz, Aaron Korostyshevsky, Vance Ley, Pravin Patel, Paul Sharps, and Tansen Varghese, "Evolution of the High Efficiency Triple Junction Solar Cell for Space Power," 33rd IEEE Photovoltaic Specialists Conference, San Diego CA, May 12-16, 2008.

19. J. Chan, J. G. Wood, and J. G. Schreiber, "Development of Advanced Stirling Radioisotope Generator for Space Exploration," Space Technology and Applications International Forum Conference, 2007, NASA/TM-2007-214806.

20. M. Dhar, Stirling Space Power Program, Volumes 1 \& 2, Final Report, NASA/CR-1999-209164 (1999).

21. Daniel Aiken, Brad Clevenger, Frederick Newman, Bruce Smith, Cory Tourino, Jerry Wilson, and Jody Wood, "The First Ten Megawatts of III-V Multi-Junction Concentrator Solar Cell Production," 33rd IEEE Photovoltaic Specialists Conference, San Diego CA, May 12-16, 2008.

22. Geoffrey S. Kinsey, Raed A. Sherif, Peichen Pien, Peter Hebert, Richard R. King, and Donald Aldrich, "Towards Commercialization Of Concentrator Multijunction Photovoltaic Modules," 33rd IEEE Photovoltaic Specialists Conference, San Diego CA, May 12-16, 2008. 